\title{
A RECENTE CONJUNTURA HIDROPRODUTIVA DO PROJETO DE IRRIGAÇÃO GORUTUBA, LOCALIZADO EM NOVA PORTEIRINHA NO NORTE DE MINAS
}

\author{
Silviane Gasparino COSTA \\ Ana Ivania Alves FONSECA ${ }^{2}$
}

\section{Resumo}

Entre os anos de 1975 e 1977, foi construída a barragem Bico da Pedra e implantou-se uma área de 740 ha irrigados, denominada de "área Piloto", situada entre os rios Gorutuba e Mosquito na bacia do rio Gorutuba. Esse projeto piloto deu início à implantação da área de irrigação conhecido hoje como Perímetro Irrigado do Gorutuba, localizado no município de Nova Porteirinha, no Norte de Minas Gerais. Esse artigo tem como objetivo a análise recente da produção irrigada e das estruturas hidráulicas que conduzem e distribuem água para os diferentes lotes do projeto. A metodologia utilizada foi a revisão bibliográfica e o trabalho de campo para a coleta de dados e aplicação de entrevistas semiestruturadas e não estruturadas. produção.

Palavras-chave: Projeto de Irrigação Gorutuba. Recursos Hídricos. Mudança de

\section{Abstract \\ The recent hydroproductive conjuncture of the Gorutuba irrigation project, located in New Porteirinha in the North of Minas}

Between 1975 and 1977, the Bico da Pedra dam was built and an area of 740 ha irrigated, known as the "Pilot area", located between the Gorutuba and Mosquito rivers in the Gorutuba river basin. This pilot project began the implantation of the irrigation area known today as the Irrigated Perimeter of Gorutuba, located in the municipality of Nova Porteirinha, in the North of Minas Gerais. This article aims at the recent analysis of irrigated production and the hydraulic structures that lead and distribute water to the different lots of the project. The methodology used was the bibliographical review and the field work for the collection of data and the application of semistructured and unstructured interviews.

Key words: Irrigation Project Gorutuba. Water resources. Production Change.

\footnotetext{
${ }^{1}$ E-mail: silviane-gaspar@hotmail.com.

2 Professora do Departamento de Geociências/Unimontes.
} 


\section{INTRODUÇÃO}

O Projeto de Irrigação Gorutuba - PGO, localizado no município de Nova Porteirinha, no Norte de Minas Gerais (Figura 1), é fruto de políticas públicas de irrigação desenvolvidas no Brasil a partir da década de 1960. Suas atividades se iniciaram em 1979, tendo a barragem Bico da Pedra como fonte hídrica aos irrigantes que se dividem entre pequenos produtores (colonos), médios e grandes empresários. As áreas dos empresários são compostas por 59 lotes e a dos colonos possuem 11 colonizações (Colonização I - também chamada de Paraguaçu, Colonização II, Colonização III, Gorutuba, Nordeste, Algodões, Caraíbas, Beira Rio, Matinha, Bico da Pedra e Mosquito) com 391 lotes. Além das áreas irrigáveis, o projeto também possui área de agricultura de sequeiro ${ }^{3}$ que é utilizada, em grande parte, para plantio do capim e do sorgo. Segundo Reis (2010, p.4), a agricultura familiar se destaca no projeto "visto que são 426 famílias trabalhando em áreas médias de 5 a 10 ha".

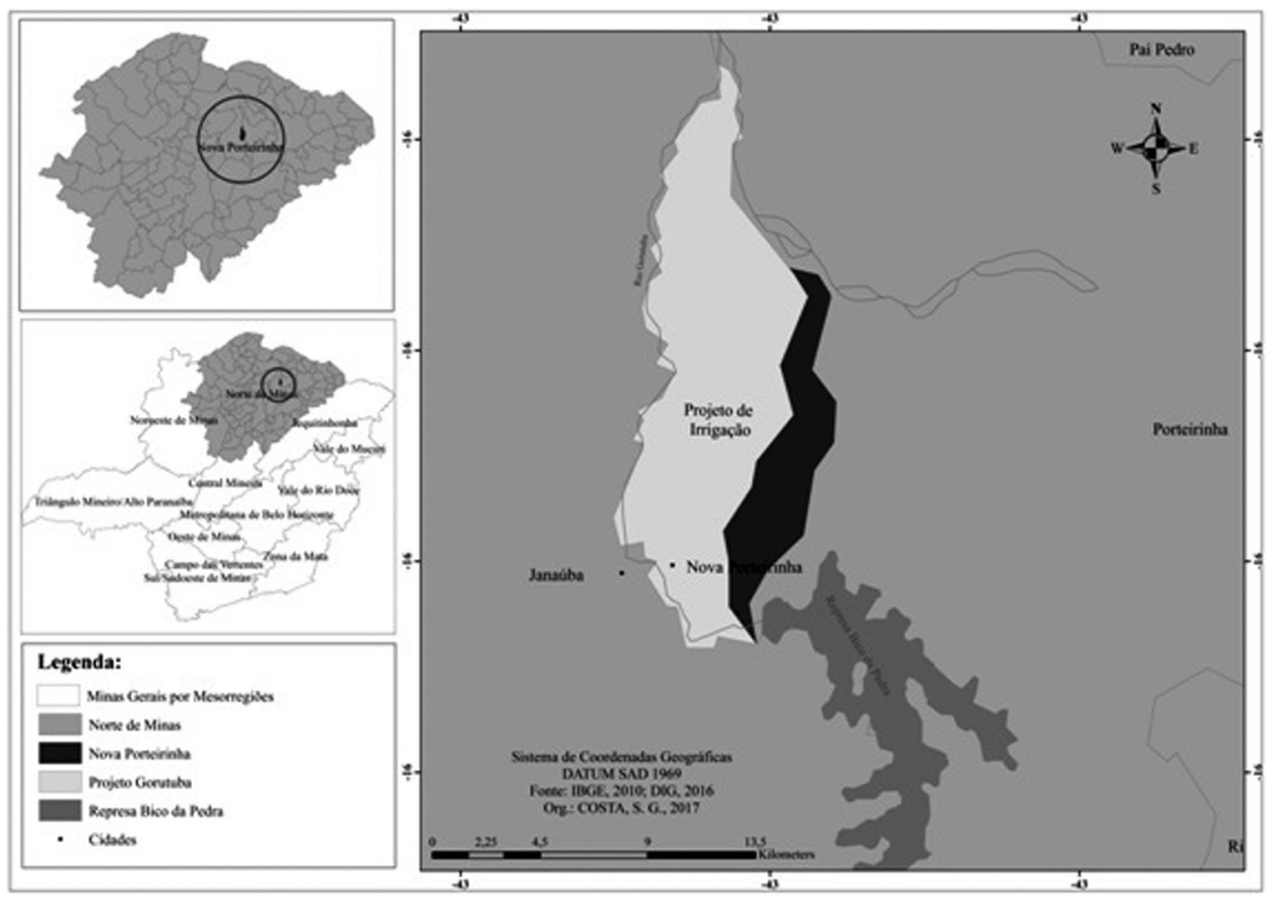

Figura 1 - Localização do Projeto Gorutuba em Nova Porteirinha-MG

Org.: COSTA, S. G., 2017.

Este estudo teve como objetivo a análise recente do projeto de irrigação Gorutuba no vale do São Francisco, porção norte do estado de Minas Gerais. A metodologia utilizada a partir de dados qualitativos foi a revisão bibliográfica para embasamento teórico; pesquisa secundária em sites institucionais e de dados estatís-

${ }_{3}$ Agricultura de sequeiro - cultivo agrícola em terrenos onde não se utiliza a tecnologia de irrigação. 
ticos. O trabalho de campo com coleta de informações em documentos foi realizada na $1^{\text {a }}$ Superintendência Regional da Companhia de Desenvolvimento dos Vales do São Francisco e Parnaíba - CODEVASF e no Departamento Nacional de Obras Contra as Secas - DNOCS, ambos localizados em Montes Claros - MG. Nas visitas in loco ao Projeto Gorutuba realizaram-se entrevistas semiestruturadas e não estruturadas com auxílio do gravador. Outros dados de campo constituem-se em anotações e fotografias retiradas no Projeto Gorutuba. Durante a construção do trabalho foram feitas diversas sistematizações que resultaram na escrita em si e na confecção de tabelas, figuras e mapas, além das transcrições dos relatos gravados para captar a essência da fala dos entrevistados.

Esse trabalho está dividido em três partes: a primeira se constitui nesta introdução, a segunda analisa a crise hídrica no projeto, a deterioração das estruturas de condução e distribuição de água e a opção pelo sistema de monocultivos, com destaque para a banana prata, banana nanica e o mogno e, na terceira parte estão as considerações finais.

\section{ESTRUTURAS DETERIORADAS E MUDANÇAS DE PRODUÇÃO NO PROJETO}

O projeto de irrigação do Gorutuba possui um total de 11.280 ha de terra, sendo que $4.885,95$ ha foram criados para serem irrigados (DIG, 2013). Em trabalho de campo realizado em maio de 2017, um representante da Empresa de Assistência Técnica e Extensão Rural - EMATER que cuida da assistência técnica aos pequenos irrigantes declarou que, atualmente, somente 1.800 ha estão sendo irrigados no PGO somando-se as duas fontes de água: barragem Bico da Pedra e os poços artesianos de cada propriedade.

Desde o ano hidrológico de 2007/2008, a barragem Bico da Pedra vem enfrentando um déficit em seu saldo de recarga, excetuando-se o ano hidrológico de 2013/ 2014 (DIG, 2015). Para tentar reparar, mesmo que de forma mínima, o saldo negativo de água na barragem, ano após ano, vem sendo implantados racionamentos sucessivos aos irrigantes do PGO. Também, estão sendo impedidas a abertura de novas áreas de cultivo ou o aumento da produção.

Após as visitas in loco e entrevistas com agricultores do PGO de diferentes colonizações, percebe-se que as atividades dos lotes só continuam viáveis pelo fato de esses agricultores terem recorrido à abertura de poços artesianos. Para os irrigantes que não aceitaram a redução drástica das suas áreas de cultivo, mesmo depois da abertura dos poços e para os que não puderam fazer essa abertura, a saída, em grande parte, foi o abandono do lote.

O Programa Mais Irrigação, lançado em novembro de 2012, previa em seu $2^{\circ}$ eixo de atuação, denominado "Implantação e Revitalização", fortificar e reestruturar perímetros públicos já existentes no país. Por meio desse programa, o Projeto Gorutuba receberia obras de reestruturação e ampliação, totalizando 5,8 mil hectares de área irrigada. O montante a ser investido, provinha de recursos da União por meio do Programa de Aceleração do Crescimento - PAC e de iniciativa privada. Com os recursos vindos desse programa, foram iniciadas obras de tubulação dos canais abertos, toda a extensão da rede de acéquias e parte do canal principal, como pode ser visto na figura 2. 


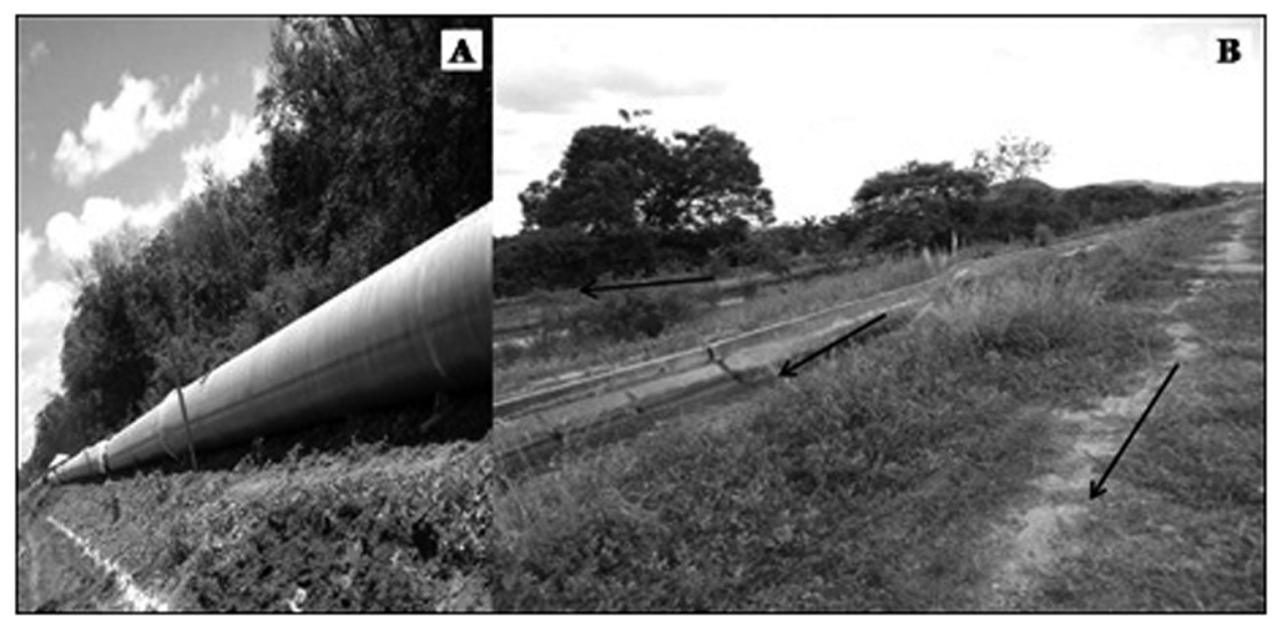

Figura 2 - Sistemas hidráulicos do Projeto Gorutuba: (A) tubulação em construção no PGO e (B) acéquia, canal principal e tubulação construída e enterrada no PGO

Fonte: (A) OLIVEIRA JÚNIOR, 2017. (B) fotografia do campo realizado em janeiro de 2017.

Porém, em 2014, as obras foram paralisadas. A tubulação dos canais do projeto significava melhoria na eficiência de condução e distribuição de água, evitando-se desperdícios. Considerando que o Projeto Gorutuba possui 39 anos de funcionamento, há um grande desgaste dessas estruturas hidráulicas, com uma série de vazamentos de água em sua rede de acéquias (Figura 3). Soma-se a esse fator que a insolação regional contribui grandemente para que haja grandes perdas por evaporação e na condução de água pelos canais abertos.

Na figura 3, é possível visualizar a deterioração das acéquias que conduzem água para os lotes dos irrigantes do projeto e uma série de vazamentos nessas estruturas. A água, recurso natural finito e indispensável à vida, é desperdiçada indiscriminadamente. Considera-se que o uso desse recurso em um perímetro irrigado deva ser feito de forma racional, levando-se em apreço que a agricultura irrigada já é a atividade que mais consome o recurso hídrico, "cerca de $80 \%$ das derivações de água"4, de modo a se evitar os desperdícios na condução, distribuição e utilização.

${ }^{4}$ Andrade. A irrigação e suas implicações sobre o capital natural em regiões áridas e semiáridas: uma revisão. 2009, p.392 


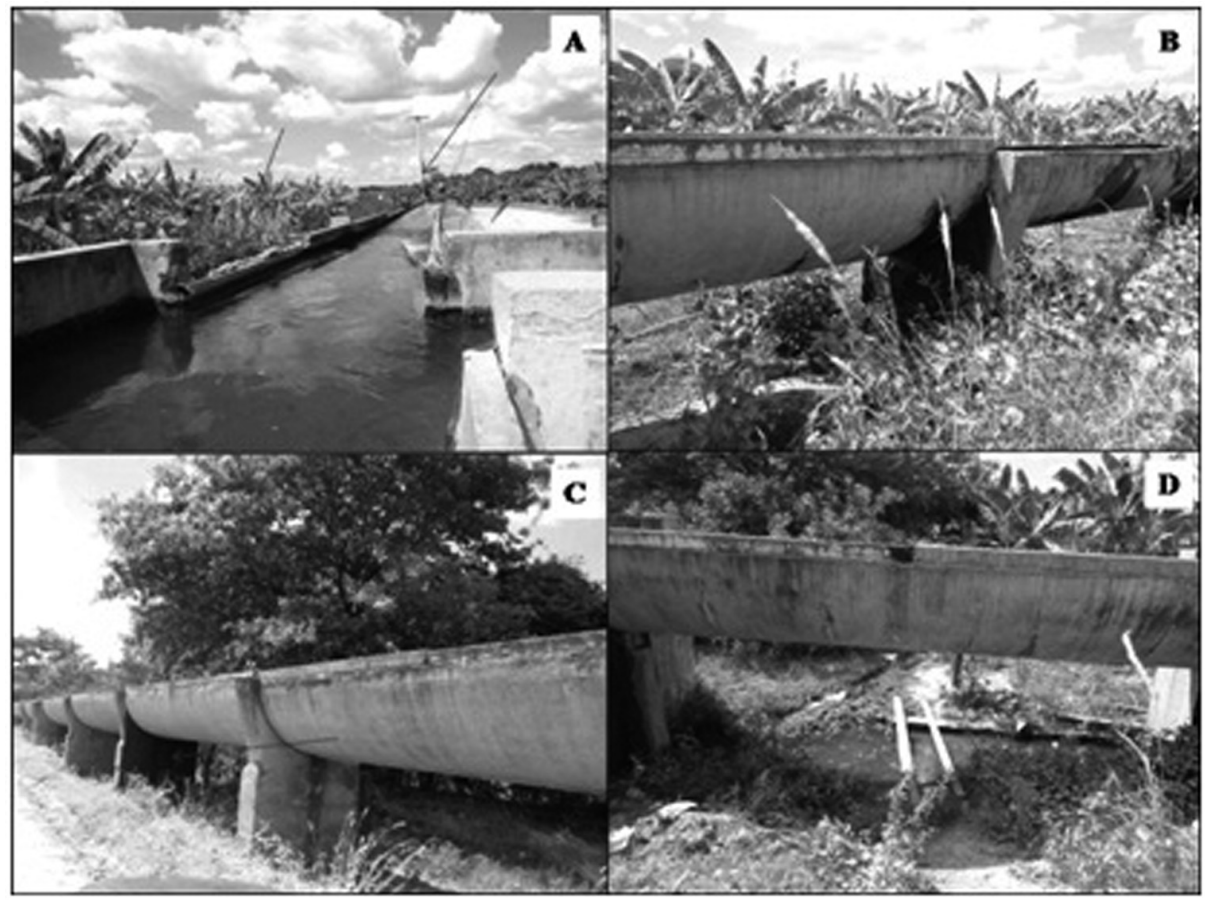

Figura 3 - Fotos das acéquias do PGO: (A) acéquia com lateral desgastada e pessoas banhando em seu interior; (B) vazamentos de água nas colunas da acéquia; (C) outro ponto de vazamento de água em coluna de acéquia; (D) formação de poça de água abaixo de acéquia com vazamento

Fonte: Visita in loco em janeiro de 2017.

Quanto ao desperdício de água, um irrigante do PGO faz o seu relato:

Quando tinha muita água a gente já perdia 40 a $50 \%$ dessa água! Hoje se nós pudéssemos, nós íamos engarrafar essa água para não desperdiçar. A gente vê, sei lá, não sei quantos quilômetros de bica5. Toda junta que monta uma bica na outra ali dá um vazamento. Não tem desconto. Então, miIhares de bicas, vinte e tantos quilômetros, imagina o desperdício. Outra coisa, a água a céu aberto: liberando a água lá em cima, tantos mil litros por segundo [...]. Quando para de irrigar lá embaixo, terminou de irrigar, ele fecha a comporta e aquela água vai embora. [...] Aqui ela é a céu aberto da boca da barragem até a derradeira área lá embaixo ela é aberto, soltou aqui, derrama lá. Usou ou não usou, derrama lá. Então a perda dela é enorme (informação verbal) ${ }^{6}$.

\footnotetext{
5 Acéquia.

6 Entrevista concedida por irrigante da colonização Paraguaçú [janeiro, 2017]. Entrevistadora: Silviane Gasparino Costa. Nova Porteirinha, 2017.
} 
Entre as melhorias a serem alcançadas com a tubulação dos canais estão: eficiência na condução e distribuição da água, evitando-se perdas; redução no consumo de água; redução dos custos de manutenção das estruturas hidráulicas; diminuição no custo da energia elétrica parcelar. (BRASIL, 2014).

A vida do projeto, a vida útil dele foi calculada para 30 anos. Porque todo mundo sabe, uma estrutura de cimento que escorre água nela, ela tem a vida útil dela. Tem muita bica aí que se der uma pancadinha nela ela esfarinha toda. Então a vida útil foi trinta anos, está com quarenta. Nós já passamos dez anos para frente. E, são dois motivos que essa obra tem que sair (canalização dos canais). Um por causa da situação da água, a gente não pode perder. MeIhora $200 \%$ o sistema de irrigação, porque ela fica como se fosse a água da COPASA. O cara chegou lá, abriu, usou, não está usando, fechou, ela está lá presa (informação verbal)7.

A obra de canalização que estava sendo implantada no PGO, de acordo com a CODEVASF (BRASIL, 2014), é do tipo tubulação pressurizada gravitacional, relevante por se aproveitar a carga hidráulica disponível no perímetro. Também, estava prevista a automatização do sistema, com monitoramento da água nas estruturas dos canais e da adutora, além da implantação de um sistema de medição parcelar do consumo de água (BRASIL, 2014).

A eficiência de distribuição de água no PGO já foi alvo de avaliações pelo TCU em 2000, quando da realização do relatório de auditoria. Nesse documento, há os seguintes dados (Tabela 1 ):

Tabela $\begin{gathered}1 \text { - Eficiência de distribuição de água no PGO } \\
\text { no período de } \mathbf{1 9 9 5 - 1 9 9 9}\end{gathered}$
\begin{tabular}{cc} 
ANO & EFICIÊNCIA (\%) \\
\hline 1995 & 53,84 \\
1996 & 63,24 \\
1997 & 60,67 \\
1998 & 52,57 \\
1999 & 58,52 \\
\hline
\end{tabular}

Fonte: BRASIL, 2000b.

Como pode ser visualizado, somente pelos anos dispostos na tabela 1 há uma perda média anual de $42,32 \%$ do recurso hídrico que é captado na barragem e fornecido ao PGO. Sobre a produção irrigada do projeto Gorutuba, analisando-se os resultados de produção de 2011 e 2014 da parte empresarial e do pequeno produtor temos (Tabelas 2, 3, 4 e 5):

7 Ibid., janeiro de 2017. 
Tabela 2 - Produção Familiar do Projeto Gorutuba em 2011

\begin{tabular}{|c|c|c|c|c|}
\hline & $\begin{array}{l}\text { ÁREA PLANTADA } \\
\text { (ha) }\end{array}$ & $\begin{array}{l}\text { ÁREA COLHIDA } \\
\text { (ha) }\end{array}$ & $\begin{array}{l}\text { PRODUÇÃO } \\
(t)\end{array}$ & $\begin{array}{l}\text { VBP* } \\
\text { (R\$) }\end{array}$ \\
\hline \multicolumn{5}{|c|}{ Lavoura Temporária: } \\
\hline Abóbora (semente) & 8 & 4 & 1,2 & $12.000,00$ \\
\hline Abóbora moranga & 7 & 6 & 72 & $30.960,00$ \\
\hline Alface & 24,9 & 18,5 & 266,4 & $319.680,00$ \\
\hline Alface (semente) & 2 & 1 & 0,1 & $1.300,00$ \\
\hline Feijão & 147,8 & 65 & 156 & $263.640,00$ \\
\hline Feijão Vagem & 8 & 6 & 24 & $28.800,00$ \\
\hline Mandioca & 22,5 & 12 & 240 & $72.000,00$ \\
\hline Melancia & 42 & 21 & 630 & $283.500,00$ \\
\hline Melancia semente & 2 & 2 & 1 & $8.000,00$ \\
\hline Melão semente & 1 & 1 & 0,5 & $5.250,00$ \\
\hline Milho Verde & 73 & 60 & 1.800 & $702.000,00$ \\
\hline Milho & 175,5 & 22,5 & 270 & $108.000,00$ \\
\hline Pimentão & 5,4 & 2 & 10 & $15.700,00$ \\
\hline Pepino (conserva) & 17 & 6,5 & 6,5 & $9.750,00$ \\
\hline Quiabo & 9,2 & 4 & 60 & $72.000,00$ \\
\hline Tomate & 6,4 & 4 & 240 & $160.800,00$ \\
\hline \multicolumn{5}{|c|}{ Lavoura Permanente: } \\
\hline Abacaxi & 2 & 1 & 30 & $23.400,00$ \\
\hline Atemoia & 2 & 1 & 8 & $36.000,00$ \\
\hline Banana Maçã & 5 & 5 & 75 & $85.500,00$ \\
\hline Banana Nanica & 61,8 & 61,8 & 2.163 & $1.492 .470,00$ \\
\hline Banana Prata & $1.348,5$ & 1.148 & 27.552 & $23.970 .240,00$ \\
\hline Caju & 1 & 1 & 15 & $86.700,00$ \\
\hline Coco & 6,5 & 6,5 & 65 & $32.500,00$ \\
\hline Goiaba & 22,9 & 18,5 & 370 & $740.000,00$ \\
\hline Laranja & 5 & 4,5 & 67,5 & $30.375,00$ \\
\hline Limão & 4,4 & 3 & 60 & $25.800,00$ \\
\hline Mamão & 21 & 12 & 600 & $588.000,00$ \\
\hline Manga Haden & & 2 & 40 & $42.800,00$ \\
\hline Maracujá & 16,7 & 9 & 180 & $126.000,00$ \\
\hline Pinha & 2 & 1 & 7 & $31.500,00$ \\
\hline Uva & 56 & 28 & 560 & $1.288 .000,00$ \\
\hline
\end{tabular}

Fonte: Adaptado de DIG, 2017.

Ao observar a tabela 2 percebe-se a grande diversidade de produtos cultivos nesse ano. As maiores áreas de produção das lavouras temporárias ficaram, em ordem decrescente, para os cultivos de milho, feijão, milho verde, melancia, alface e mandioca. Nas lavouras perenes, os cultivos de banana prata, banana nanica, uva, goiaba, mamão e maracujá tiveram as maiores áreas de plantio. A opção pela produção diversificada assegura a oferta de alimentos aos brasileiros, contribuindo com a segurança alimentar e nutricional, pois gera o barateamento dos preços (MDA, 2016). 
Tabela 3 - Produção Empresarial do Projeto Gorutuba em 2011

\begin{tabular}{|c|c|c|c|c|}
\hline & $\begin{array}{l}\text { ÁREA PLANTADA } \\
\text { (ha) }\end{array}$ & $\begin{array}{l}\text { ÁREA COLHIDA } \\
\text { (ha) }\end{array}$ & $\begin{array}{c}\text { PRODUÇÃO } \\
(\mathrm{t})\end{array}$ & $\begin{array}{l}\text { VBP* } \\
(\mathrm{R} \$)\end{array}$ \\
\hline \multicolumn{5}{|c|}{ Lavoura Temporária: } \\
\hline Abóbora & 5 & 5 & 50 & $12.500,00$ \\
\hline Feijão carioca & 1 & 1 & 1,8 & $2.683,80$ \\
\hline Milho & 21,1 & 17 & 67,6 & $13.623,40$ \\
\hline Milho semente & 16,2 & 16,2 & 32 & $25.600,00$ \\
\hline Pepino & 8 & 4 & 20 & $17.800,00$ \\
\hline Sorgo & 1 & 1 & 10 & $1.500,00$ \\
\hline Tomate & 1 & 1 & 40 & $14.000,00$ \\
\hline \multicolumn{5}{|c|}{ Lavoura Permanente: } \\
\hline Banana prata & 1.016 & 906 & 21.744 & $17.395 .200,00$ \\
\hline Banana nanica & 39 & 39 & 1.092 & $753.480,00$ \\
\hline Coco & 10 & 4 & 9,16 & $10.991,37$ \\
\hline Goiaba & 1 & 0,1 & 1,5 & $3.000,00$ \\
\hline Mamão & 72 & 50 & 2.000 & $1.960 .000,00$ \\
\hline Manga & 77 & 64 & 1.280 & $1.369 .600,00$ \\
\hline Uva & 10 & 10 & & $1.183 .350,00$ \\
\hline \multicolumn{3}{|c|}{ Total Temporária e Permanente (VBP): } & \multicolumn{2}{|c|}{$\begin{array}{c}1.183 \cdot 350,00 \\
\mathbf{R} \mathbf{2 2} \cdot \mathbf{7 6 3 \cdot 3 2 8 , 5 7}\end{array}$} \\
\hline
\end{tabular}

Fonte: Adaptado de DIG, 2017.

Para a agricultura empresarial do PGO, em 2011, as maiores áreas de plantio nas lavouras temporárias foram a do milho e milho verde (Tabela 3). Já no que concerne aos cultivos perenes, as maiores áreas são reservadas à banana prata, manga, mamão e banana nanica. Nota-se que a diversidade de espécies cultivadas pelos empresários é bem menor do que na agricultura familiar. Outros cultivos, além dos dispostos nas tabelas 2 e 3, são praticados no PGO, mas não estão sendo divulgados em termos de produção (t) e Valor Bruto da Produção - VBP. Por isso, acredita-se que esses produtos são para consumo interno. Mesmo assim, até a diversidade de produção desses, com o passar do tempo, sofreu brusca decaída.

Com o passar dos anos, diminuiu-se a variedade de produtos cultivados, optando-se, geralmente, pelos mais rentáveis economicamente, razão inversa quanto ao consumo de água, pelo fato de se ter optado pela monocultura, com espécies exigentes desse líquido. Assim, os dados de produção mais recentes da agricultura irrigada do PGO divulgados pelo Distrito de Irrigação do Gorutuba - DIG e pela CODEVASF são do ano de 2014, demonstrados nas tabelas 4 e 5 .

Tabela 4 - Produção Familiar do Projeto Gorutuba em 2014

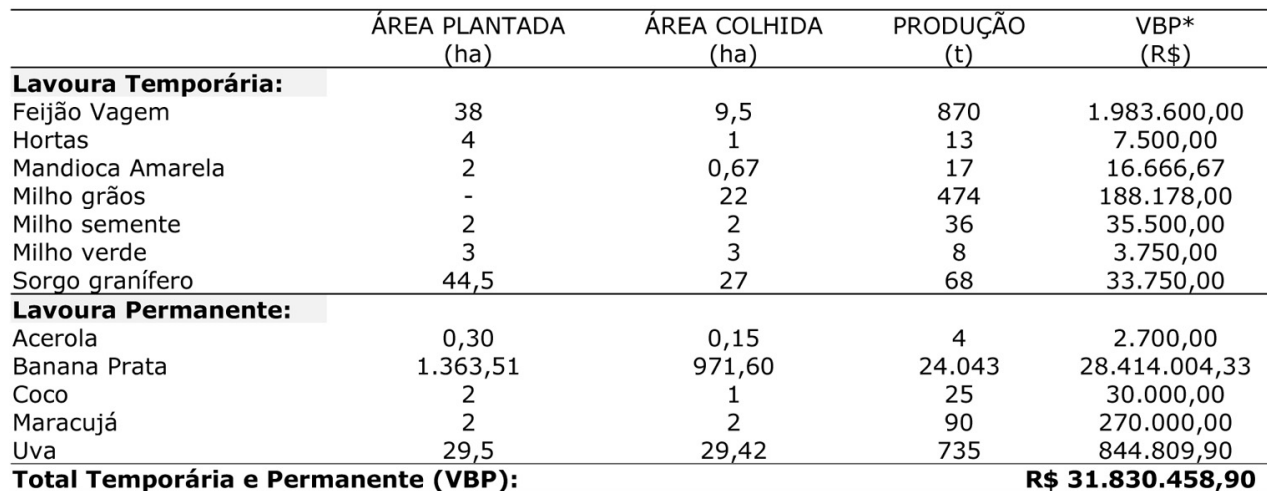

Fonte: Adaptado de DIG, 2017. 
Ao observar a tabela 4 atenta-se para a diminuição da diversidade de cultivos produzidos pela agricultura familiar do PGO. As maiores áreas de lavoura temporária, em 2014, foram designadas ao sorgo granífero, feijão vagem e milho em grãos. Já nas lavouras perenes, a banana prata e a uva apresentaram as maiores áreas de cultivo.

Tabela 5 - Produção Empresarial do Projeto Gorutuba em 2014

\begin{tabular}{lcccc}
\hline & $\begin{array}{c}\text { ÁREA PLANTADA } \\
(\mathrm{ha})\end{array}$ & $\begin{array}{c}\text { ÁREA COLHIDA } \\
(\mathrm{ha})\end{array}$ & $\begin{array}{c}\text { PRODUÇÃO } \\
(\mathrm{t})\end{array}$ & $\begin{array}{c}\text { VBP* } \\
(\mathrm{R} \$)\end{array}$ \\
\hline Lavoura Temporária: & - & 1,5 & 6 & $1.398,44$ \\
Milho em grãos & & & & \\
\hline Lavoura Permanente: & 55 & 44,69 & 1.335 & $1.081 .350,00$ \\
Banana nanica & $1.078,4$ & 848,45 & 24.944 & $31.179 .687,5$ \\
Banana prata & 85 & 92,08 & 1.700 & $2.720 .000,00$ \\
Manga Palmer & 13,6 & 27,2 & 109 & $76.160,00$ \\
Uva & & & & $\mathbf{R \$ 3 5 . 0 5 8 . 5 9 5 , 9 4}$ \\
\hline
\end{tabular}

Fonte: Adaptado de DIG, 2017.

Os resultados da parte empresarial do PGO, em 2014, conforme a tabela 5, apontam a opção pela fruticultura irrigada, com destaque para a banana prata, manga Palmer, banana nanica e uva. Nos dois períodos analisados, 2011 e 2014 percebese que as maiores áreas de produção são destinadas para o cultivo da banana prata. Outros cultivos importantes no PGO, mas que não estão sendo divulgados em termos de quantidade produzida ( $t$ ) e Valor Bruto de Produção em 2014 são o capim, a canade-açúcar, hortaliças, frutíferas diversas, o eucalipto e o mogno, de acordo com a tabela 6. Acredita-se que o capim e a cana-de-açúcar são para alimentação animal, as hortaliças e frutíferas diversas, para consumo interno das propriedades rurais.

O eucalipto é mais recente no projeto. Por ser uma árvore, necessita de um tempo maior para se desenvolver e ficar apta para o corte; já o mogno está sendo computado desde o primeiro ano (2010) em que foram divulgados os resultados de cultivos do PGO. Os valores auferidos não estão sendo expressos nas tabelas disponibilizadas pelo DIG e pela CODEVASF.

Tabela 6 - Plantio de Mogno no PGO

\begin{tabular}{|c|c|c|c|c|c|}
\hline \multirow{2}{*}{$\begin{array}{l}\text { CLASSE DO } \\
\text { AGRICULTOR }\end{array}$} & \multicolumn{5}{|c|}{ ÁREA PLANTADA (ha) POR PERÍODO } \\
\hline & 2010 & 2011 & 2012 & 2013 & 2014 \\
\hline Familiar & 67,2 & 66,2 & 57,5 & $\begin{array}{l}46,4 \\
374\end{array}$ & $\begin{array}{c}28 \\
374\end{array}$ \\
\hline
\end{tabular}

Fonte: Adaptado de DIG, 2017.

Ao observar a tabela 6 é possível depreender que há uma diminuição das áreas de plantio de mogno a cada ano, porém, os respectivos valores auferidos não estão sendo divulgados pelo DIG e pela CODEVASF. O mogno, atualmente no Projeto Gorutuba, é o segundo produto mais cultivado, perdendo apenas para a banana. Nas visitas de campo realizadas para esse trabalho em 2016 e 2017 observou-se que, visualmente, os plantios de banana e mogno sobressaem grandemente, de modo a não se identificar, no geral, outros cultivos.

O estudo socioeconômico feito no baixo Gorutuba apontou a viabilidade de produção de artigos como arroz, feijão, milho e outros cultivos já praticados no Vale 
e que seriam absorvidos pela população da própria região. Em vista disso, em entrevista feita em janeiro de 2017, obteve-se o seguinte relato:

O projeto era voltado para grãos. Grãos é muito mais fácil comercializar bem depois. O grão você pode armazenar para vender depois. A fruta você tem que vender de imediato. E aí nós ficamos sem a cooperativa, porque a cooperativa já estava falida. Ela não entrou nesse mercado de frutas para comercializar. Foi quando surgiu a FRUCOOP, que era uma cooperativa de um grupo de produtores, nem todo mundo era sócio. Aí nós ficamos na mão de atravessadores. Você vendia a banana e recebia pouco, ou seja, no preço que eles queriam. Se fosse uma cooperativa como a COVAG tanto ela teria crescido, tinha se mantido por que já era uma cooperativa grande, como tinha sido ótimo para os produtores [...] aqui produzia arroz, feijão, milho. A banana, eu não lembro muito mas, ela entrou uns dez anos depois (INFORMAÇÃO VERBAL, ENTREVISTA CONCEDIDA POR EX-AGRICULTOR DA COLONIZAÇÃO BICO DA PEDRA. [JANEIRO, 2017]. ENTREVISTADOR: ANA IVANIA ALVES FONSECA, NOVA PORTEIRINHA, 2017).

Todavia, os cultivos mais importantes relatados e visualizados em campo, atualmente, por ordem de grandeza são: banana prata, mogno, mamão e uva.

\section{CONSIDERAÇÕES FINAIS}

O Projeto Gorutuba é um perímetro irrigado de conotação pública que, ao longo de sua história, abrigou várias estruturas que favoreceram diferentes atores sociais. Localizado na margem direita do rio de mesmo nome, especificamente em um espaço denominado de baixo Gorutuba, é conhecido por sua destacada fertilidade natural que beneficiou a sua ocupação territorial por pequenos produtores rurais.

Quando foi implantando era voltado, principalmente, para a produção de grãos (arroz, feijão, milho), além de hortaliças e verduras, que eram vendidos no mercado regional. Atualmente, o PGO produz prioritariamente, os monocultivos de banana e mogno. A comercialização desses produtos é exportada para os mercados de São Paulo, Rio de Janeiro, Belo Horizonte, Brasília e Salvador.

No tocante às obras de infraestrutura do Projeto, faz-se necessária a renovação periódica da técnica, de modo a se caminhar concomitantemente com a evolução da ciência e tecnologia e da eficiência no uso da água, o que acarretaria em economia financeira e contenção de desperdícios. Por enquanto, tudo o que tem sido feito está à mercê das ações de um determinado governo e de seus interesses políticos. Esse é o caso da construção das tubulações do PGO que foram paralisadas pelo atual governo, não desejoso de assumir a continuação dos projetos de uma política anterior. 


\section{REFERÊNCIAS}

BRASIL. Lei no 9.433, de 08 de janeiro de 1997. Institui a Política Nacional de Recursos Hídricos, cria o Sistema Nacional de Gerenciamento de Recursos Hídricos, regulamenta o inciso XIX do art. 21 da Constituição Federal. Diário Oficial da União, Brasília, 08 jan. 1997.

BRASIL. Ministério da Integração Nacional. Companhia de Desenvolvimento do Vale do São Francisco - CODEVASF. Projeto de irrigação do Vale do Rio Gorutuba margem esquerda. Documento $\mathrm{n}^{\circ} 1$ - Relatório (texto). Montes Claros: $1^{a}$ Superintendência Regional - HYDROS, junho de 1980.

BRASIL. Tribunal de Contas da União - TCU. Auditoria operacional. CODEVASF. Projetos de irrigação do Gorutuba e de Lagoa Grande MG. Descontinuidade da prestação dos serviços de assistência técnica e extensão rural aos colonos. Ineficiência nos mecanismos de aferição e controle do consumo de água nos perímetros. Determinação. Juntada às contas. DC-0394-40/00-2. Identidade do documento: Decisão 394/2000 Segunda Câmara. Processo: 005.497/2000-3. ATA 40/2000. Diário Oficial da União, Brasília, de 13 nov. 2000.

BRASIL. Planalto. Programa Mais Irrigação. Disponível em: < www2. planalto.gov.br/acompanhe-o-planalto/caderno-destaques/edicoes-anterioreslista-de-pdf/gestao-em-destaque/programa-mais-irrigacao > >.Publicado em 09/04/ 2013 no Portal do Planalto. Acesso: 09/10/2017.

BRASIL. Ministério da Integração Nacional. Melhorias no Gorutuba permitirão aumento da área irrigada e geração de empregos. 30 maio 2014. Disponível em: <<http://www.codevasf.gov.br/noticias/2014/melhorias-no-gorutuba-permitiraoaumento-da-area-irrigada-e-geracao-de-empregos/>>. Acesso em: 09 maio 2017.

DISTRITO DE IRRIGAÇÃO DO PERÍMETRO GORUTUBA - DIG. Caracterização do Perímetro de Irrigação do Gorutuba. Disponível em: <<http://www.dig.org.br/ home/>>. Janaúba: setembro de 2013. Acesso em: 13 jan. 2016.

Distrito de Irrigação do Perímetro Gorutuba - DIG. Caracterização do Perímetro de Irrigação do Gorutuba. Disponível em: $<<$ http://www.dig.org.br/home/ $>>$. Janaúba: setembro de 2015. Acesso: 13/01/2016.

DISTRITO DE IRRIGAÇÃO DO PERÍMETRO GORUTUBA - DIG. Questionário enviado ao DIG. Junho de 2017.

HERMANO, Vivian Mendes. Janaúba/MG: uma cidade média no Norte de Minas Gerais. 2016. Tese (Doutorado em Geografia), Pontifícia Universidade Católica de Minas Gerais -PUCMinas, Belo Horizonte, 2016.

INSTITUTO BRASILEIRO DE GEOGRAFIA E ESTATÍSTICA - IBGE. Divisão regional. Disponível em: <<Acesso: 27/11/2016.

LEITE, Marcos Esdras; DIAS, Lucimar Sales; ROCHA, André Medeiros. Análise da ocupação no entorno da barragem Bico da Pedra, no município de Janaúba/MG. Caderno de Geografia. V.25, n.44, 2015.

ministério do desenvolvimento agrário. Programa de Aquisição de Alimentos. MDA, 2016 Disponível em: <<http://www.mda.gov.br/sitemda/secretaria/ saf-paa/sobre-o-programa>> Acesso em: 09/10/2017.

MINAS GERAIS. Secretaria de Estado de Agricultura, Pecuária e Abastecimento. Empresa de Assistência Técnica e Extensão Rural do Estado de Minas Gerais - EMATERMG. Entrevista com técnico. Janaúba, 2015. 
MINAS GERAIS. Secretaria de Estado da Agricultura de Minas Gerais. Departamento de Estudos Rurais, Departamento Nacional de Obras Contra as Secas - DNOCS. Estudo sócio-econômico e programa preliminar para a região do Baixo GorutubaMG. Belo Horizonte, 1969.

REIS, Paulo Ricardo da Costa. Análise do nível de desenvolvimento socioeconômico da região Norte de Minas Gerais antes e após a implantação dos perímetros públicos de irrigação. In: ENCONTRO DE ADMINISTRAÇÃO PÚBLICA E GOVERNANÇA. 28 a 30 de novembro. Vitória: EnAPG, 2010. 